\title{
Rules of conduct
}

SADJ March 2019, Vol. 74 No. 2 p98-p99

WG Evans

The Medical and Dental Council publishes Rules of Conduct $^{1}$ which cover all the registered professions. In an endeavour to clarify how the Rules may be applied, a series of case examples were published by $\mathrm{T}$ Verschoor. ${ }^{2}$ Although that publication appeared in 1990, the examples cited remain relevant to the Rules as they have been amended to date.

The cases summarised below demonstrate how the Council interprets the Rules... and also how members may transgress.

\section{RULE 6 - Itinerant practice}

A practitioner may conduct a regularly recurring itinerant practice at a place where another practitioner is established if, in such itinerant practice, such practitioner renders the same level of service to patients, at the same fee as the service which he or she would render in the area in which he or she is conducting a resident practice.

Case: Dentists intended to use a caravan for the delivery of dental services at distant towns at regular intervals.

Ruling: It was decided this was permissible provided that a full professional service was rendered and that only towns having no resident dentist were visited.

\section{RULE 9 - Covering}

A practitioner shall employ as a professional assistant or locum tenens, or in any other contractual capacity and, in the case of locum tenens for a period not exceeding six months, only a person - (a) who is registered under the Act to practise in independent practice; (b) whose name currently appears on the register kept by the registrar in terms of section 18 of the Act; and (c) who is not suspended from practising his or her profession. [Subrule (1) substituted by GN R68/2009] (2) A practitioner shall help or support only a person registered under the Act, the Pharmacy Act, 1974 (Act No. 53 of 1974), the Nursing Act, 1978 (Act No. 50 of 1978), the Social Service Professions Act, 1978 (Act No. 110 of 1978), the Dental Technicians Act, 1979 (Act No. 19 of 1979), or the Allied Health Professions Act, 1982 (Act No. 63 of 1982), if the professional practice or conduct of such person is legal and within the scope of his or her profession.

Case: A dentist wished to make use of a non-professional hypnotist in his practice.

Ruling: It was decided that the Councils ethical rules prohibit the use of unregistered persons for the purposes of hypnosis during professional treatments.

WG Evans: Managing editor, Email: bill.evans@wits.ac.za
Case: A dentist's wife placed and cemented crowns on a patient's central incisors.

Ruling: The dentist was found guilty of disgraceful conduct. He was suspended from practice for six months, which suspension was conditionally deferred for three years.

\section{RULE 10 - Supersession}

A practitioner shall not supersede or take over a patient from another practitioner if he or she is aware that such patient is in active treatment of another practitioner, unless he or she - (a) takes reasonable steps to inform the other practitioner that he or she has taken over the patient at such patient's request; and (b) establishes from the other practitioner what treatment such patient previously received, especially what medication, if any, was prescribed to such patient and in such case the other practitioner shall be obliged to provide such required information.

Case: A dentist had over twenty years continually held various Provincial maxillo-facial posts. He had dealt with patients suffering jaw fracture cases being referred to him by private practitioners.

The dentist had the opinion that as the patient had been referred to him, treatment could proceed with no consultation with the dentist of the patient. He requested a ruling from the Council.

Ruling: It was decided that he should firstly ask a patient who his dentist was. if the patient had his own dentist, he then had to decide in consultation with the latter whether to continue treatment or to refer the patient to his own dentist.

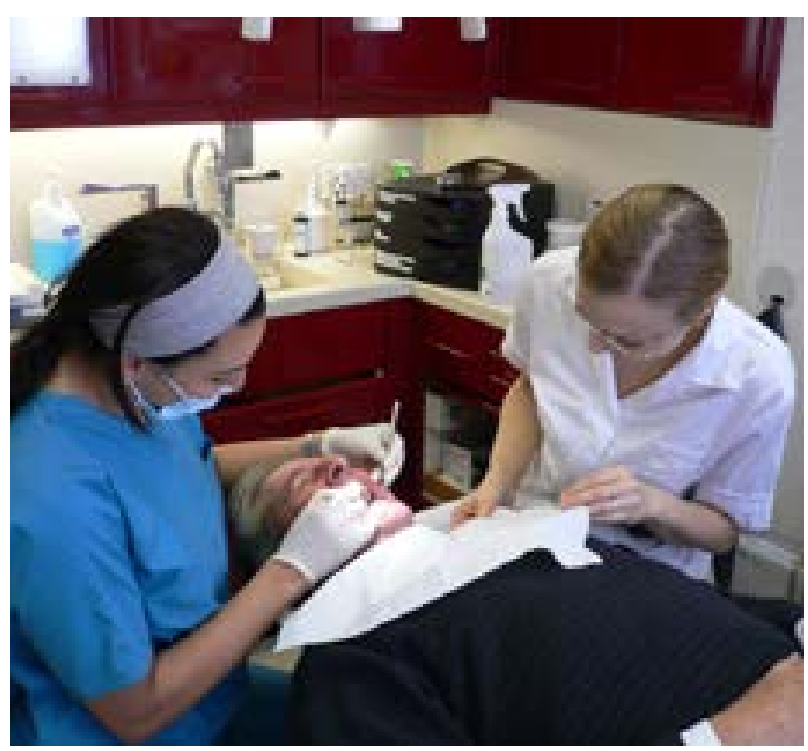




\section{RULE 16 - Certificates and reports}

(1) A practitioner shall grant a certificate of illness only if such certificate contains the following information - (a) the name, address and qualification of such practitioner; (b) the name of the patient; (c) the employment number of the patient (if applicable); (d) the date and time of the examination; (e) whether the certificate is being issued as a result of personal observations by such practitioner during an examination, or as a result of information which has been received from the patient and which is based on acceptable medical grounds; ( $f$ ) a description of the illness, disorder or malady in layman's terminology with the informed consent of the patient: Provided that if such patient is not prepared to give such consent, the practitioner shall merely specify that, in his or her opinion based on an examination of such patient, such patient is unfit to work; $(\mathrm{g})$ whether the patient is totally indisposed for duty or whether such patient is able to perform less strenuous duties in the work situation; (h) the exact period of recommended sick leave; (i) the date of issue of the certificate of illness; and (j) the initial and surname in block letters and the registration number of the practitioner who issued the certificate.

(2) A certificate of illness referred to in subrule (1) shall be signed by a practitioner next to his or her initials and surname printed in block letters. (3) If preprinted stationery is used, a practitioner shall delete words which are not applicable. (4) A practitioner shall issue a brief factual report to a patient where such patient requires information concerning himself or herself.

Case: A dentist submitted a medical certificate he had completed himself as a claim for sick benefits from a provident fund. He claimed falsely that he had been examined by a physician and had been advised that he would be unable to practice for a period as a result of backache.

Ruling: It was decided that the practitioner was guilty of disgraceful behaviour. He was suspended from practice for six months.

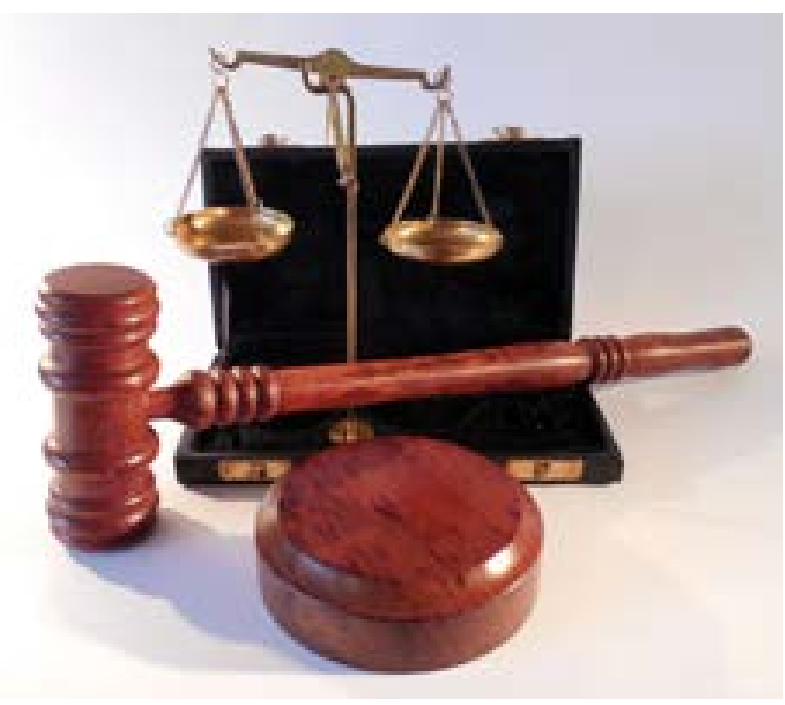

Being alert to the Rules of Conduct is a prerequisite to proper ethical practice.

\section{References}

1. Ethical Rules Of Conduct For Practitioners Registered Under The Health Professions Act, 1974. Published under Government Notice R717 in Government Gazette 29079 of 4 August 2006 and amended by GN R68 GG 3182520090202 GN R654 GG 3340020100730

2. Verschoor, T. Verdicts of the Medical Council. Digma Publications, Pretoria, 1990. ISBN 0869848887. 